\title{
TORACOTOMIA DE REANIMAÇÃO: RACIONALIZAÇÃO DO USO DO PROCEDIMENTO
}

\section{RESUSCITATIVE THORACOTOMY: RATIONALIZATION OF THE PROCEDURE}

\author{
Gustavo Pereira Fraga, TCBC-SP'; Elaine Barberato Genghini²; Mario Mantovani, ECBC-SP'; \\ Larissa Garcia de Oliveira Cortinas²; Waldemar Prandi Filho, TCBC-SP ${ }^{4}$
}

\begin{abstract}
RESUMO: Objetivo: Contesta-se a aplicação indiscriminada da toracotomia de reanimação (TR) no trauma. Este estudo objetiva reavaliar as indicações de TR na nossa instituição. Método: Estudo retrospectivo envolvendo 126 pacientes submetidos à TR entre janeiro de 1995 e dezembro de 2004. Definiram-se quatro grupos considerando os sinais vitais dos pacientes na admissão: morto ao chegar, fatal, agônico e choque profundo. O protocolo incluiu dados como mecanismo de trauma, sinais vitais, Escore de Trauma Revisado (Revised Trauma Score ou RTS), locais de lesão (identificados durante cirurgia ou autópsia), Índice de Gravidade da Lesão (Injury Severity Score ou ISS) e sobrevida. Resultados: Setenta e dois $(57,2 \%)$ pacientes apresentavam ferimento por projétil de arma de fogo, $11(8,7 \%)$ ferimento por arma branca e $43(34,1 \%)$ por trauma fechado. Nenhum dos sessenta pacientes $(47,6 \%)$ dos grupos fatal e morto ao chegar sobreviveu, mas $13(39,4 \%)$ dos pacientes fatais foram encaminhados ao centro cirúrgico (CC) para tratamento definitivo. Dos 66 pacientes dos grupos agônico e choque profundo, $44(66,7 \%)$ foram submetidos a TR no prontosocorro (PS) e $31(70,5 \%)$ destes foram transferidos até o CC. Nos 22 restantes, a parada cardiorrespiratória ocorreu já no CC, onde foi feita a TR. Dois pacientes do grupo choque profundo sobreviveram (1,6\% do total) e receberam alta com função cerebral normal. O ISS médio foi 33, sendo exsangüinação a causa mais freqüente de óbito. Conclusão: Resultados ruins enfatizam a necessidade de uma abordagem mais seletiva para aplicar a TR. Um algoritmo baseado no mecanismo de trauma e nos sinais vitais na admissão é proposto para otimizar as indicações de TR (Rev. Col. Bras. Cir. 2006; 33(6): 354-360).
\end{abstract}

Descritores: Toracotomia; Ressuscitação cardiopulmonar; Massagem cardíaca; Traumatismos torácicos.

\section{INTRODUÇÃO}

Atualmente, observa-se nos hospitais, um aumento no número de pacientes proporcional ao aumento da violência urbana. $\mathrm{O}$ avanço no campo das ciências médicas tem permitido a inúmeras dessas vítimas, que sofreram trauma grave, e que anteriormente não possuíam condições fisiológicas que lhes garantisse alguma perspectiva de sobrevida, a possibilidade de serem salvas ${ }^{1,2,3}$. Isso certamente se deve à melhorias importantes que ocorreram tanto na abordagem préhospitalar quanto no transporte e no cuidado com as vítimas de trauma ${ }^{3,4,5,6}$. Cabe ressaltar que as novas técnicas e tecnologias podem ser usadas nesses pacientes, mas questões econômicas forçam uma consideração da relação custobenefício ${ }^{1}$. Destacando-se o fato de que muitos destes pacientes estão num estado dito extremo, muitas vezes caracterizado por uma parada cardíaca iminente, podemos citar a toracotomia de reanimação (TR) como exemplo de manobra agressiva que pode ser utilizada ${ }^{2,3,5,7,8}$. Entretanto, ao se pesquisar na literatura dados sobre a definição de TR, o tipo de paciente em que deve ser indicada, os fatores prognósticos e os resultados esperados, observa-se que o tema perma- nece controverso, não havendo um protocolo bem estabelecido para sua aplicação.

Assim, o objetivo do presente estudo é realizar uma análise crítica dos casos de TR atendidos no serviço, analisando principalmente a indicação e os resultados do procedimento, além de apresentar o protocolo para a realização da TR adotado pela Disciplina de Cirurgia do Trauma da Unicamp após a conclusão deste estudo.

\section{MÉTODO}

Foi realizado estudo retrospectivo envolvendo 126 casos de pacientes atendidos pela Disciplina de Cirurgia do Trauma do Departamento de Cirurgia no Hospital das Clínicas da Unicamp, que foram submetidos à TR no período entre janeiro de 1995 e dezembro de 2004.

As toracotomias foram classificadas como sendo de "reanimação" (TR) quando foram realizadas em pacientes em condições extremas, como parte integral do processo de reanimação, podendo o procedimento ter ocorrido na cena da lesão, na sala de emergência ou no centro cirúrgi$\mathrm{co}^{5,8,9,10}$.

\footnotetext{
1. Médico Assistente Doutor da Disciplina de Cirurgia do Trauma da FCM - UNICAMP e do Departamento de Cirurgia do Hospital Municipal Dr. Mário Gatti.

2. Aluna de graduação da FCM-Unicamp; Membro da Liga do Trauma da FCM - UNICAMP

3. Professor Titular e Chefe da Disciplina de Cirurgia do Trauma da FCM - UNICAMP.

4. Médico Assistente da Disciplina de Cirurgia do Trauma da FCM - UNICAMP.

Recebido em 05/06/06

Aceito para publicação em 07/07/06

Conflito de interesses: nenhum

Fonte de financiamento: nenhuma

Trabalho realizado na Disciplina de Cirurgia do Trauma do Departamento de Cirurgia da Faculdade de Ciências Médicas (FCM) da Universidade Estadual de Campinas (UNICAMP).
} 
No Serviço, a TR é um procedimento realizado através de incisão torácica ântero-lateral, no quinto espaço intercostal esquerdo, em pacientes com diagnóstico clínico de parada cárdio-respiratória (PCR) após traumatismo, independente do mecanismo de trauma. A TR é realizada preferencialmente na sala de urgência de admissão do paciente, sendo realizada no centro cirúrgico de urgência (CC) quando o paciente apresenta sinais de vida na admissão e evolui com PCR no percurso ou ao dar entrada neste local. A TR não é habitualmente indicada no serviço para pacientes em choque profundo, pois nessa situação realiza-se o procedimento no $\mathrm{CC}$, denominando-o toracotomia de emergência, sem o diagnóstico do local da hemorragia. Em casos isolados, de pacientes com trauma abdominal com lesão grave e exsangüinação sem PCR, em que optou-se por toracotomia para clampeamento da aorta descendente, o procedimento não é considerado TR. A realização da TR cabe ao médico residente em cirurgia do trauma sob supervisão do cirurgião assistente.

As informações necessárias para o preenchimento do protocolo elaborado para este estudo foram obtidas diretamente dos prontuários dos pacientes (incluindo as fichas de atendimento inicial no pronto-socorro e os laudos de cirurgia) e nos laudos de exame necroscópico do Instituto Médico Legal de Campinas. Todas as informações foram registradas em programa EPI-INFO contendo as seguintes variáveis: data de admissão no serviço, sexo, idade, tipo de traumatismo (fechado ou penetrante), mecanismo de trauma, classificação de Rohman et $a l^{10}$ conforme sinais vitais (Tabela 1), índices de trauma, momento em que foi realizada a intubação orotraqueal, local onde foi realizada a TR, hemotransfusões realizadas, lesões encontradas, evolução, tempo decorrido entre admissão e óbito, local e causa do óbito.

Os índices de trauma aplicados nos pacientes estudados foram: Escala de Coma de Glasgow (Glasgow Coma Scale ou ECG), Escore de Trauma Revisado (Revised Trauma

Tabela 1 - Situação clínica dos pacientes na admissão hospitalar, modificada de Rhoman et al ${ }^{10}, 1983$.

\section{Morto ao chegar}

Clinicamente morto

Sem sinais de vida no percurso.

\section{Fatal}

Inconsciente

Sem sinais vitais

Sem respiração espontânea

Sem atividade física espontânea, mas com algum sinal de vida no percurso.

\section{Agônico}

Semiconsciente

Pulsos finos

Respiração ofegante

\section{Choque profundo}

Consciente

Pressão sangüínea sistólica menor ou igual a 70mmHg.
Score ou RTS), Índice de Gravidade da Lesão (Injury Severity Score ou ISS) e Probabilidade de Sobrevida (Índice misto ou TRISS $)^{11-14}$. A ECG é utilizada para avaliar o nível de consciência dos pacientes ${ }^{11}$. O RTS é considerado um índice fisiológico que usa para seu cálculo diferentes dados, como a ECG, a pressão arterial sistólica e a freqüência respiratória, com diferentes constantes, com valor máximo de 7,84, que representa paciente admitido em boas condições clínicas ${ }^{11}$. O ISS é um índice anatômico que em cada segmento corpóreo considera a lesão mais grave, sendo selecionados os três segmentos que apresentam lesão com maior pontuação. Tais valores são elevados ao quadrado, sendo a soma dos mesmos o resultado do ISS $^{13}$. Sua variação é de o a 75 , com pontuação de gravidade crescente, considerando-se traumatismos graves aqueles com valor acima de 25 . Finalmente, o TRISS é um índice misto obtido após associar o RTS, o ISS, a idade do paciente (menor ou igual a 54 anos ou maior que 54 anos) e o tipo de traumatismo (fechado ou penetrante), sendo que o valor obtido representa a probabilidade de sobrevida estimada para o traumatizado ${ }^{14}$.

Os sobreviventes foram definidos como aqueles pacientes que receberam alta do hospital vivos ${ }^{15}$.

\section{RESULTADOS}

A maioria dos pacientes era do sexo masculino (111 casos $-88,1 \%$ ). A faixa etária variou de 1 a 76 anos, com média de 31,6 anos e mediana de 29,5 anos. Houve predomínio da faixa etária entre 20 e 40 anos ( 87 casos - 69\%).

Quanto ao mecanismo de trauma, houve um número maior de traumas penetrantes ( 83 casos $-65,9 \%$ ), como ilustrado na Figura 1.

No momento da admissão, na sala de urgência, os pacientes foram classificados conforme os sinais vitais em quatro sub-grupos, sendo: morto ao chegar (27 casos - 21,4\%), fatal (33 casos - 26,2\%), agônico (39 casos - 31\%) e choque profundo $(27$ casos $-21,4 \%)$.

O RTS teve uma média de 1,7 e uma mediana de 0,3. A Tabela 2 mostra a média do RTS para cada sub-grupo atribuído conforme os sinais vitais dos pacientes na admissão.

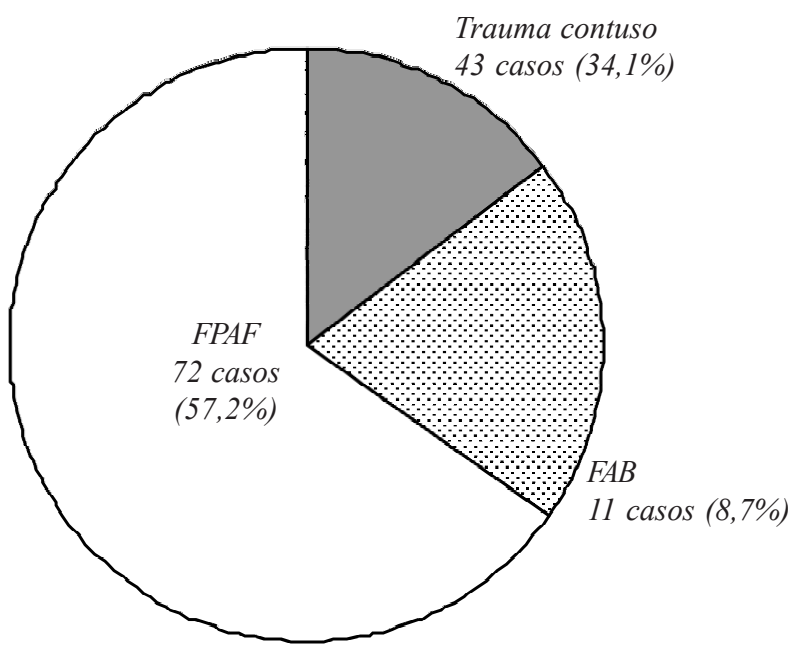

Figura 1 - Número de pacientes e porcentagem conforme o mecanismo de trauma. 
A obtenção de uma via aérea "definitiva" foi conseguida através da realização de intubação orotraqueal, sendo que 31 pacientes $(24,6 \%)$ tiveram esse procedimento realizado no atendimento pré-hospitalar.

A TR foi realizada na sala de emergência em 97 pacientes $(77 \%)$. Em três pacientes a TR foi realizada em hospitais secundários, onde estes foram reanimados e posteriormente transferidos para a UNICAMP, o último constituindo um dos dois pacientes sobreviventes da presente casuística. Houve um paciente de 54 anos, em tratamento não-operatório de lesão hepática e esplênica, que evoluiu com PCR no sexto dia de internação, sendo realizada a TR na enfermaria, com sucesso na reanimação e realização de tratamento definitivo no CC (o paciente evoluiu para óbito por coagulação intravascular disseminada). Em outros 25 pacientes (19,8\% do total), o diagnóstico de PCR foi feito logo na admissão na sala de cirurgia, onde foi realizada a TR.

Entre os 66 pacientes dos grupos agônico e choque profundo, 44 (66,7\%) evoluíram com PCR na sala de emergência, e destes, em $31(70,5 \%)$ a resposta foi satisfatória com a TR, sendo estes pacientes encaminhados ao CC. Nos outros 22 pacientes destes grupos a PCR ocorreu já no CC,

Tabela 2 - Média de RTS dos pacientes conforme o sub-grupo dos sinais vitais.

\begin{tabular}{lcc}
\hline Classificação & Número de pacientes & Média do RTS \\
\hline Morto ao chegar & $27(21,4 \%)$ & 0,00 \\
Fatal & $33(26,2 \%)$ & 0,00 \\
Agônico & $39(31,0 \%)$ & 1,73 \\
Choque profundo & $27(21,4 \%)$ & 5,24 \\
\hline
\end{tabular}

Tabela 3 - Número de casos conforme o segmento corpóreo lesado e o mecanismo de trauma.

\begin{tabular}{lcc}
\hline & $\begin{array}{c}\text { Traumatismo } \\
\text { fechado }\end{array}$ & $\begin{array}{c}\text { Traumatismo } \\
\text { penetrante }\end{array}$ \\
\hline Trauma de crânio & 25 casos & 12 casos \\
Trauma torácico & 36 casos & 65 casos \\
Trauma abdominal & 34 casos & 49 casos \\
Trauma de bacia & 9 casos & 1 caso \\
\hline
\end{tabular}

Tabela 4 - Valores médios de ISS conforme o mecanismo de trauma e o grupo (sinais vitais na admissão).

\begin{tabular}{lc}
\hline & Média do ISS \\
\hline Mecanismo de trauma & \\
$\quad$ Trauma penetrante - 83 casos & 29,8 \\
Trauma fechado - 43 casos & 39,1 \\
Grupo na admissão & 34,9 \\
$\quad$ Morto ao chegar - 27 casos & 30,1 \\
Fatal - 33 casos & 33,2 \\
Agônico - 39 casos & 34,2 \\
Choque profundo - 27 casos & \\
\hline
\end{tabular}

sendo prontamente realizada a TR. Já entre os 33 pacientes do grupo fatal, apenas $13(39,4 \%)$ tiveram o procedimento efetivo e foram encaminhados ao CC. Nenhum dos 27 pacientes do grupo morto ao chegar se beneficiou da TR para ser encaminhado ao $\mathrm{CC}$.

Em relação às lesões anatômicas, foi constante o achado de lesões em mais de uma localização nos pacientes, sendo que $101(80,2 \%)$ apresentavam trauma torácico, $83(65,9 \%)$ apresentavam traumatismo abdominal, 37 (29,4\%) apresentavam traumatismo craniano e $10(7,9 \%)$ apresentavam fratura de bacia. A Tabela 3 ilustra o acometimento pela lesão traumática dos segmentos torácico, abdominal, bacia e traumatismo craniencefálico (TCE), nos diferentes mecanismos de trauma. Os órgãos e estruturas lesados com maior freqüência foram: pulmão ( 78 casos), fígado (41 casos), coração (22 casos), grandes vasos abdominais ( 20 casos) e grandes vasos do tórax (14 casos).

Em relação ao ISS, houve uma variação de 10 a 75, com média de 32,9 . Em 48 pacientes $(38,1 \%)$ o ISS era menor ou igual a 25. A média de ISS variou conforme o mecanismo de trauma, sendo um pouco maior nos traumas contusos. Os valores foram muito próximos se analisados os grupos conforme os sinais de vida na admissão hospitalar (Tabela 4).

Comparando-se os valores do ISS entre os pacientes submetidos a TR e que morreram na sala de emergência (60 casos; média de ISS de 34) e os que receberam tratamento definitivo para reparo das lesões no CC (66 casos no total; com média de ISS de 32), não foi observada diferença estatística entre os grupos.

Porém, ao se analisar os índices fisiológicos, os que não receberam tratamento definitivo tiveram um RTS médio de 0,52 , contra uma média de 2,69 naqueles que foram operados para reparo das lesões no CC.

A mortalidade foi de 98,4\%. Apenas dois pacientes $(1,6 \%)$ sobreviveram. O primeiro caso foi de uma jovem de 33 anos, grávida de oito meses, vítima de colisão automobilística, admitida com RTS de 6.18. Foi encaminhada ao centro cirúrgico onde foi constatado $\mathrm{PCR}$, sendo realizada TR e laparotomia. A paciente apresentava volumoso hemoperitônio, com lesão esplênica grau IV, sendo tratada com esplenectomia. Foi realizada cesareana para retirada do feto (Apgar, no primeiro minuto, de 2). Na evolução, foi diagnosticada lesão de brônquio fonte esquerdo, tratada cirurgicamente. Apesar da internação prolongada, mãe e fillho sobreviveram, sem seqüelas.

O segundo caso foi de um homem de 21 anos vítima de ferimento por arma branca na fossa supraclavicular esquerda. O paciente recebeu o primeiro atendimento num hospital secundário, onde foi realizada a TR devido a hemotórax volumoso, choque hipovolêmico refratário e bradicardia, sendo encaminhado à Unicamp após receber sangue. Durante o transporte observou-se melhora clínica das condições do paciente. Foi admitido em choque profundo, com ECG de oito e RTS de 3,91, evoluindo para PCR na admissão, sendo levado ao centro cirúrgico, onde foi reanimado com sucesso, tendo recebido tratamento cirúrgico das lesões (lesão de $80 \%$ da artéria axilar esquerda, lesão puntiforme na veia subclávia esquerda e lesão do plexo braquial à esquerda). O paciente evoluiu 
Tabela 5 - Causas de óbito dos pacientes submetidos à TR e respectivas porcentagens.

\begin{tabular}{lcc}
\hline Causa do óbito & Número de casos & Porcentagem (\%) \\
\hline Hemorragia/coagulopatia & 104 & 83,9 \\
Lesão cerebral + hemorragia/coagulopatia & 14 & 11,3 \\
Lesão cerebral & 4 & 3,2 \\
Insuficiência respiratória & 1 & 0,8 \\
Insuficiência respiratória + insuficiência renal + hemorragia/coagulopatia & 1 & 0,8 \\
\hline
\end{tabular}

bem, recebendo alta hospitalar em 9 dias, permanecendo, entretanto, com pequena seqüela motora no membro superior esquerdo.

Dentre os 124 casos de pacientes que não sobreviveram, a causa de óbito identificada com maior freqüência foi hemorragia/coagulopatia (104 casos - 83,9\%). A Tabela 5 mostra as causas de óbito.

Em 75 pacientes $(60,5 \%)$ o óbito foi constatado até a primeira hora após a admissão. Nos 49 que resistiram a este período, o intervalo de tempo entre a admissão e o óbito, bem como o local em que este ocorreu, está ilustrado na Figura 2.

Em 93 casos $(73,8 \%)$ foi realizado o levantamento do laudo necroscópico dos pacientes a fim de detalhar as lesões que levaram o paciente a óbito. Nos demais pacientes as lesões foram identificadas ainda no CC durante a tentativa de reparo.

O TRISS teve uma média de 0,17 . Ocorreram 20 casos ( $16 \%$ ) de óbito não esperado, com TRISS maior ou igual a 0,50 . Entre os sobreviventes, o TRISS foi de 0,56 para a mulher e de 0,59 para o homem.

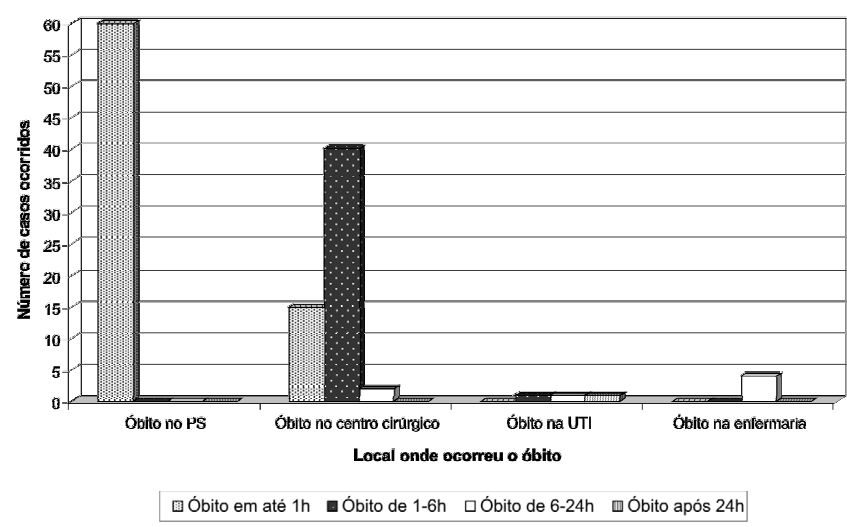

Figura 2 - Número de casos conforme o intervalo de tempo entre a admissão / óbito e o local onde ocorreu o óbito.

\section{DISCUSSÃO}

Embora a TR seja um procedimento cuja origem reside em 1874, com a promoção da massagem cardíaca aberta por Schiff, ela tornou-se popular por volta de 1960 com o refinamento das técnicas de cirurgia cardíaca ${ }^{2,16}$.

Entretanto, mesmo passados quase 50 anos desde a sua popularização, tal procedimento ainda não está bem estabelecido na literatura médica mundial, sendo que o tema permanece controverso apesar dos inúmeros estudos existentes.
Muitos problemas ocorrem quando estes são comparados ou combinados ${ }^{1,5}$.

A literatura disponível é confusa, principalmente devido ao fato de não haver uniformidade na terminologia usada, o que impede uma comparação entre casuísticas a fim de se estabelecer resultados exatos ${ }^{3,17}$. O nome do procedimento e o local onde é executado são expressos de modo inconsistente: toracotomia de emergência, toracotomia ressuscitativa, toracotomia imediata também são termos usados na literatura a fim de se referir à toracotomias realizadas na sala de emergência ou no $\mathrm{CC}^{1,2}$. Além disso, a maioria dos estudos lida com um número relativamente pequeno de pacientes e, portanto, informações estatisticamente significantes não podem ser obtidas.

Os objetivos primários da TR são: aliviar o tamponamento cardíaco, controlar a hemorragia decorrente da lesão de vasos intratorácicos ou de lesão cardíaca, eliminar o intenso embolismo aéreo ou a fístula broncopleural, executar a massagem cardíaca aberta e ocluir a aorta torácica descendente temporariamente a fim de priorizar o fluxo sangüíneo para o miocárdio e para o cérebro, além de atenuar hemorragias subdiafragmáticas ${ }^{2,5,7}$. O propósito, portanto, é realizar uma tentativa de reanimação durante a abordagem inicial do paciente traumatizado e daquele que, sustentando ferimentos iminentemente fatais, apresenta rápida deterioração hemodinâmica logo após a chegada à sala de emergência ${ }^{7}$. Uma vez que os sinais vitais retornam, as prioridades na reanimação passam a ser: otimizar a função cardíaca e maximizar a oferta de oxigênio para os tecidos ${ }^{2}$. Deve-se ter em mente que a manobra envolvendo o clampeamento da aorta implica em sérias conseqüências, visto que ocorre uma acidose lática importante secundária ao metabolismo anaeróbio do extenso território vascular submetido à isquemia distalmente à região do clampeamento. Pode ocorrer, inclusive, a "síndrome do desclampeamento aórtico", com acidose metabólica grave e muitas vezes irreversível, quando o tempo de clampeamento for superior a 30 - 45 minutos ${ }^{3}$.

Assim, aplicação ótima da TR requer um entendimento dos seus objetivos fisiológicos, das manobras técnicas, das conseqüências cardiovasculares e metabólicas e das indicações clínicas. O seu valor no paciente crítico e que ainda não está morto é inquestionável, embora seu uso indiscriminado o torne um procedimento pouco produtivo e de alto custo $^{2,18}$.

Uma revisão adequada da literatura não deixa dúvidas de que a melhor aplicação para a TR ocorre quando o paciente em questão foi vítima de um ferimento único pene- 
trante no tórax e apresenta sinais de vida na admissão ${ }^{19,20,21}$. Alguns estudos também identificaram a presença de tamponamento cardíaco associada à maior chance de sobrevi$\operatorname{ver}^{20}$. Na presente casuística, uma das pacientes que sobreviveu não se encaixa neste perfil de bom prognóstico. Fraga et $a l^{22}$, em estudo realizado no Instituto Médico Legal de Campinas com 1976 casos de óbito por causas externas num período de dois anos, identificaram 359 casos de trauma cardíaco, dentre os quais apenas $5,6 \%$ chegaram a receber tratamento efetivo em ambiente hospitalar. Isto ratifica a informação de que poucos pacientes com trauma cardíaco chegam com sinais de vida aos serviços hospitalares ${ }^{22,23}$.

De acordo com o Suporte de Vida Avançado no Trauma (Advanced Trauma Life Support, ATLS ${ }^{\circledR}$ ), o único paciente com indicação para TR é aquele que foi vítima de trauma penetrante em tórax e apresenta-se sem pulso, porém com atividade elétrica cardíaca. Excluem-se, portanto, traumas fechados, mesmo com atividade elétrica cardíaca ${ }^{24}$.

Entretanto, diversas correntes de cirurgiões advogam outras aplicações para a TR, sendo que muitos incluem pacientes fatais ou vítimas de trauma fechado em seus atendi$\operatorname{mentos}^{17,18,25}$.

Após um período de uso liberal, o entusiasmo pela TR declinou devido ao seu limitado sucesso e ao aumentado risco de exposição da equipe de saúde a agentes infecciosos durante o procedimento ${ }^{15,26}$. Assim, atualmente está sendo preferível uso de protocolos pré-estabelecidos de acordo com a experiência de cada serviço ${ }^{27}$. Estes, quando bem aplicados, demonstram que a TR não apenas pode salvar vidas, mas também possui uma boa relação custo-benefício $^{18}$. Quanto ao benefício, é inquestionável o valor de tratar um traumatizado com indicação precisa de TR, principalmente se este sobreviver sem seqüelas neurológicas. Porém, o custo de uma TR em um paciente que evolui a óbito na sala de urgência varia de US\$ 892 a US\$ 1660 , enquanto o custo para o paciente que evolui para óbito no CC varia de US\$ 3500 a US $\$ 5823^{1,19}$. Outro fator que deve ser ressaltado é o risco de acidentes biológicos envolvendo a equipe de saúde que, mesmo com as devidas precauções, pode se contaminar com instrumental ou com fragmentos de costela fraturada, na ansiedade de realizar o procedimento com rapidez. Caplan et $a l^{26}$, em estudo realizado com 984 pacientes vítimas de trauma, demonstraram que $26 \%$ dos pacientes tinham evidência de exposição a um ou mais destes agentes: HIV (4\%), vírus da hepatite B (20\%) e vírus da hepatite $\mathrm{C}(14 \%)$. Trinta e oito por cento dos pacientes apresentavam mais de uma sorologia positiva. A incidência destas doenças é maior em vítimas de trauma admitidas na sala de urgência do que na população em geral, e ainda maior na população submetida à $\mathrm{TR}^{5,26}$.

A possibilidade de se obter êxito depende muito do estado fisiológico do paciente na admissão, do tempo de PCR, do sítio e do número de lesões associadas. Estes são tidos como fatores prognósticos importantes para o sucesso do procedimento. Talvez, o local onde ocorreu a PCR seja um divisor de águas entre a maior possibilidade de sucesso ou de fracasso, pois estudos revelam que a grande maioria dos sobreviventes que não evoluíram com graves repercussões neu- rológicas apresentava sinais de vida na admissão e sofreram PCR já dentro do hospital ${ }^{28}$.

Em relação à indicação da TR no atendimento préhospitalar, Powell et al ${ }^{21}$, em estudo realizado em 26 pacientes sobreviventes que necessitaram de RCP com massagem cardíaca externa no pré-hospitalar, observaram que a TR poderia ser útil em casos selecionados. O procedimento está contra-indicado em pacientes com trauma contuso e RCP superior a 15 minutos $^{21}$. Coats et al ${ }^{29}$, do Serviço de Resgate Aéreo de Londres, estudaram retrospectivamente 39 casos de toracotomia no pré-hospitalar em pacientes com trauma penetrante de tórax, com sobrevida de 10\% (4 casos), todos vítimas de ferimento por arma branca. Na realidade daquele serviço, que é muito diferente da observada no Brasil, a TR deve ser considerada em pacientes com PCR desde que se tenha uma equipe médica experiente e treinada dentro de um sistema de trauma e que o tratamento cirúrgico definitivo demore mais do que 10 minutos para ser realizado ${ }^{29}$. Na nossa experiência, desaconselhamos a realização de TR no ambiente pré-hospitalar. Um dos nossos sobreviventes foi submetido à TR em um hospital secundário, porém em condições adequadas.

É certo que os traumas fechados constituem a indicação mais polêmica para a realização de TR, dado que diferentes estudos têm demonstrado a escassez de sucesso neste grupo de pacientes. Deve-se levar em conta que após um trauma fechado os pacientes tendem a sofrer lesões em diversos sistemas tendo, portanto, diversas fontes potenciais de hemorragia. Os valores de ISS mais elevados nos pacientes com trauma contuso na presente casuística comprovam a maior gravidade das lesões neste subgrupo de pacientes. Além disso, vítimas de trauma fechado estão constantemente em choque ou em coagulopatia já na avaliação inicial ${ }^{30}$.

A sobrevida de pacientes submetidos à TR após trauma contuso na maioria das séries varia de 0 a $2 \%$, chegando a $6 \%$ quando o paciente é admitido com sinais vitais presentes ${ }^{1,4,5,9,18,19,27,31-33}$. Há autores que referem que em casos bem selecionados uma pequena porcentagem de pacientes consegue sobreviver, inclusive sem seqüelas, o que tornaria justificável a realização da manobra' ${ }^{1,4,27,31}$.

Já nos traumas penetrantes, os resultados são um pouco mais animadores. Biffl $e t a l^{2}$, em 2004, revendo a literatura, constataram algumas tendências de sobrevida em pacientes submetidos a TR em centros de trauma. Aproximadamente $15 \%$ dos pacientes sobrevivem quando admitidos em choque profundo, $10 \%$ sobrevivem quando apresentavam sinais de vida na admissão e apenas 3\% sobrevivem quando admitidos sem sinais de vida. Quando o trauma é por arma branca, em média $20 \%$ dos casos sobrevivem, caindo para $6 \%$ de sobrevida nos ferimentos por arma de fogo. Pacientes com lesão isolada de coração admitidos em choque têm sobrevida próxima de $50 \%$, caindo para $20 \%$ quando são atendidos sem sinais de vida ${ }^{2}$.

Embora nenhum sobrevivente da nossa casuística pertencesse ao grupo pediátrico, estudos reforçam que os fatores para indicação de TR devam ser os mesmos dos adultos, já que os resultados nestas populações são semelhantes $^{5,28,34}$. 
A análise específica da nossa casuística mostrou alguns dados divergentes das tendências da literatura, como se observa a seguir.

A nossa indicação para a realização de TR foi extremamente liberal sem, entretanto, agregar benefícios, fato comprovado pelo elevado número de TRs realizadas em pacientes que não apresentavam sinais de vida na admissão (47,6\% do total), sendo que nenhum paciente deste grupo sobreviveu. $\mathrm{O}$ grande número de TRs realizadas nestes grupos de pacientes talvez reflita a relutância de muitos cirurgiões em declarar tais pacientes mortos antes de tentarem todos os esforços para reanimá-los ${ }^{25,35}$. Além disto, trata-se de hospital universitário, e é sabido que todo médico residente em cirurgia do trauma, mesmo sob supervisão docente, ambiciona salvar um paciente em condições extremas, exagerando na indicação da TR, embora isto seja importante na sua formação. Desconsiderando-se os pacientes classificados como "mortos ao chegar" e "fatais", nossa porcentagem de sobreviventes subiria para 3\%, muito mais adequada para as casuísticas atualmente disponíveis. Em questionário enviado a cirurgiões da Associação Americana de Cirurgia do Trauma (American Association for the Surgery of Trauma, AAST), também foi observado uma indicação liberal de TR, sendo que muitos indicaram o procedimento em trauma contuso, contrariando as recomendações do ATLS $^{\circledR 17,23}$. Isto demonstra que o tema continua controverso.

Os dois pacientes sobreviventes na nossa casuística não correspondem ao grupo clássico de eleição para a realização de TR (ferimento único penetrante em tórax), o que nos leva a concordar com aqueles que defendem a realização do procedimento para o paciente em condições extremas, desde que este apresente sinais de vida na admissão. A Figura 3 ilustra o protocolo atualmente utilizado pela Disciplina para a indicação da TR.

Concluindo, com base no nosso estudo retrospectivo, fica evidente a necessidade de se implantar um protocolo para racionalizar o emprego da TR, a fim de se aumentar o número de pacientes salvos e de se evitar gastos e exposição da equipe de saúde desnecessariamente. Para a nossa realidade, parece ser mais adequado empregar um modelo de protocolo que se baseie na presença ou não de sinais de vida na admissão, já que não houve sobreviventes entre os pacientes sem sinais de vida na admissão, fato também observado em outros centros pelo mundo.

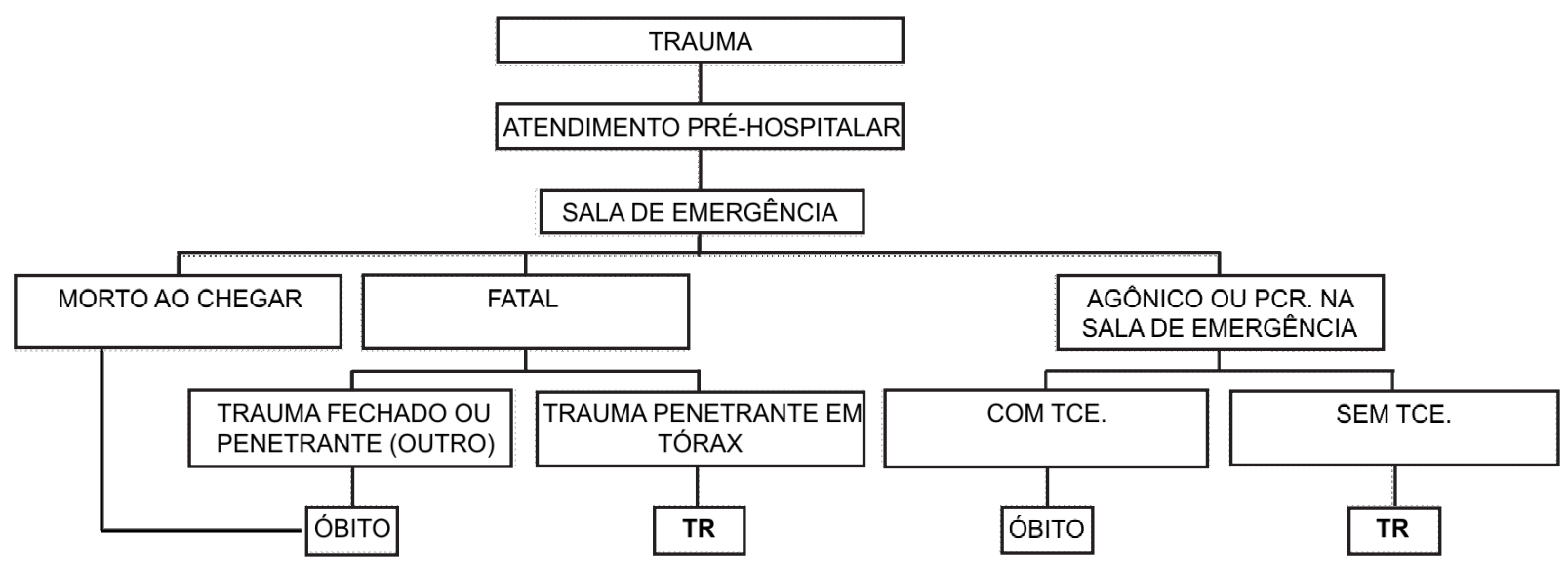

Figura 3 - Algoritmo utilizado pela Disciplina de Cirurgia do Trauma da FCM - Unicamp para indicação de TR.

\begin{abstract}
Background: This study was designed to reassess the indications for TR in our institution. Methods: A retrospective study of 126 patients undergoing TR from January 1995 to December 2004 was performed. Four groups were defined based on the severity of their injuries: death on arrival, fatal, agonal and profound shock. Database included variables such as mechanism of trauma, vital signs, Revised Trauma Score (RTS), sites of injury (identified during surgery or autopsy), Injury Severity Score (ISS) and survival. Results: The mechanism of injury was gunshot wound in 72 (57,2\%) patients, stab wound in 11 (8,7\%) and blunt trauma in 43 (34,1\%). Sixty patients (47,6\%) had no vital signs (death or fatal groups) on admission at the Emergency Department (ED); although none of them survived, 13 (39,4\%) fatal patients survived to reach the operating room (OR). In the agonal and profound shock groups (66 patients), 44 (66,7\%) had $T R$ in the ED and 31 (70,5\%) reached the OR. In the remaining 22, cardiorespiratory arrest occurred in the OR, where the TR was performed. Two patients in profound shock survived (1,6\% of the total) and were discharged with normal neurologic function. The ISS average was 33 and exsanguination was the most frequent cause of death. Conclusion: Our results indicate poor outcome and further emphasizes the need for a more selective approach in the application of TR. An algorithm based on mechanism of injury and vital signs on admission at ED is proposed to optimize the indications of TR.
\end{abstract}

Key words: Thoracotomy; Cardiopulmonary resuscitation; Heart massage; Thoracic injuries. 


\section{REFERÊNCIAS}

1. Boyd M, Vanek VW, Bourguet CC. Emergency room resuscitative thoracotomy: when is it indicated? J Trauma. 1992;33(5):71421.

2. Biffl WL, Moore EE, Johnson JL. Emergency Department Thoracotomy. In: Moore EE, Feliciano DV, Mattox KL, editors. Trauma. 5th ed. McGraw-Hill Companies; 2004. p. 239-253

3. Coimbra R. Toracotomia na sala de emergência. In: Souza HP, Breigeiron R, Gabiatti G, editores. Cirurgia do Trauma: condutas diagnósticas e terapêuticas. $1^{\text {a }}$ ed. São Paulo: Atheneu; 2003. p. 119-126.

4. Kavolius J, Golocovsky M, Champion HR. Predictors of outcome in patients who have sustained trauma and who undergo emergency thoracotomy. Arch Surg. 1993;128(10):1158-62.

5. Hunt PA, Greaves I, Owens WA. Emergency thoracotomy in thoracic trauma - a review. Injury. 2006;37(1):1-19. Epub 2005 Apr 20.

6. Mantovani M. Suporte básico e avançado de vida no trauma. São Paulo: Atheneu; 2005.

7. Brown SE, Gomez GA, Jacobson LE, Scherer T, McMillan RA. Penetrating chest trauma: should indications for emergency room thoracotomy be limited? Am Surg. 1996;62(7):530-3; discussions 533-4.

8. Saad Jr R, Rasslan R. Trauma de tórax em geral. In: Freire E, editor. Trauma: a doença dos séculos. $1^{\mathrm{a}}{ }^{\mathrm{e}}$ ed. São Paulo: Atheneu; 2001. p. 1365-1375.

9. Grove CA, Lemmon G, Anderson G, McCarthy M. Emergency thoracotomy: appropriate use in the resuscitation of trauma patients. Am Surg. 2002;68(4):313-6; discussion 316-7.

10. Rohman M, Ivatury RR, Steichen FM, Gaudino J, Nallathambi MN, Khan M, Stahl WM. Emergency room thoracotomy for penetrating cardiac injuries. J Trauma. 1983;23(7):570-6.

11. Teasdale G, Jennett B. Assessment of coma and impaired consciousness. A practical scale. Lancet. 1974;2(7872):81-4.

12. Champion HR, Sacco WJ, Copes WS, Gann DS, Gennarelli TA, Flanagan ME. A revision of the trauma score. J Trauma. 1989;29(5):623-9.

13. Baker SP, O’Neill B, Haddon Jr W, Long WB. The injury severity score: a method for describing patients with multiple injuries and evaluating emergency care. J Trauma. 1974;14(3):187-96.

14. Boyd CR, Tolson MA, Copes WS. Evaluating trauma care: the TRISS method. Trauma Score and the Injury Severity Score. J Trauma. 1987; 27(4):370-8.

15. Aihara R, Millham FH, Blansfield J, Hirsch EF. Emergency room thoracotomy for penetrating chest injury: effect of an Institutional protocol. J Trauma. 2001;50(6):1027-30.

16. Millham FH, Grindlinger GA. Survival determinants in patients undergoing emergency room thoracotomy for penetrating chest injury. J Trauma. 1993;34(3):332-6.

17. Miglietta MA, Robb TV, Eachempati SR, Porter BO, Cherry R, Brause J, Barie PS. Current opinion regarding indications for emergency department thoracotomy. J Trauma. 2001;51(4):6706.

18. Baker CC, Thomas AN, Trunkey DD. The role of emergency room thoracotomy in trauma. J Trauma. 1980;20(10):848-55.

19. Cogbill TH, Moore EE, Millikan JS, Cleveland HC. Rationale for selective application of Emergency Department thoracotomy in trauma. J Trauma. 1983;23(6):453-60.

20. Karmy-Jones R, Nathens A, Jurkovich GJ, Shatz DV, Brundage S, Wall MJ Jr, Engelhardt S, Hoyt DB, Holcroft J, Knudson MM, Michaels A, Long W. Urgent and emergent thoracotomy for penetrating chest trauma. J Trauma. 2004;56(3):664-8, discussion 668-9.
21. Powell DW, Moore EE, Cothren CC, Ciesla DJ, Burch JM, Moore JB, Johnson JL. Is emergency department resuscitative thoracotomy futile care for the critically injured patient requiring prehospital cardiopulmonary resuscitation? J Am Coll Surg. 2004;199(2):211-215.

22. Fraga GP, Heinzl LR, Longhi BS, Silva DC, Fernandes Neto FA, Mantovani M. Trauma cardíaco: estudo de necropsias. Rev Col Bras Cir. 2004;31(6):386-90.

23. Baccarin V, Rizoli SB, Vieira RW, Mantovani M. Ferimentos cardíacos penetrantes. Experiência com 21 casos. Rev Col Bras Cir. 1992;19(3):112-5.

24. American College of Surgeons. Advanced Trauma Life Support. Student Manual. $7^{\mathrm{a}}$ ed. Chicago: American College of Surgeons; 2002.

25. Cera SM, Mostafa G, Sing RF, Sarafin JL, Mattews BD, Heniford BT. Physiologic predictors of survival in post-traumatic arrest. Am Surg. 2003;69(2):140-4

26. Caplan ES, Preas MA, Kerns T, Soderstrom C, Bosse M, bansal J, Constantine NT, Hendrix E, Caplan M. Seroprevalence of human immunodeficiency virus, hepatitis B virus, hepatitis C virus, and rapid plasma reagin in a trauma population. J Trauma. 1995;39(3):533-7, discussion 537-8.

27. Baxter BT, Moore EE, Moore JB, Cleveland HC, McCroskey BL, Moore FA. Emergency department thoracotomy following injury: critical determinants for patient salvage. World J Surg. 1988;12(5):671-5.

28. Lorenz HP, Steinmetz B, Lieberman J, Schecoter WP, Macho JR. Emergency thoracotomy: survival correlates with phisiologic status. J Trauma. 1992;32(6):780-5; discussion 785-8.

29. Coats TJ, Keogh S, Clark H, Neal M. Prehospital resuscitative thoracotomy for cardiac arrest after penetrating trauma: rationale and case series. J Trauma. 2001;50(4):670-3.

30. Hoth JJ, Scott MJ, Bullock TK, Stassen NA, Franklin GA, Richardson JD. Thoracotomy for blunt trauma: traditional indications may not apply. Am Surg. 2003;69(12):1108-11.

31. Branney SW, Moore EE, Feldhaus KM, Wolfe RE. Critical analysis of two decades of experience with postinjury emergency department thoracotomy in a regional trauma center. J Trauma. 1998;45(1):87-94; discussion 94-5.

32. Ivatury RR, Kazigo J, Rohman M, Gaudino J, Simon R, Stahl WM. "Directed" emergency room thoracotomy: a prognostic prerequisite for survival. J Trauma. 1991;31(8):1076-81; discussion 1081-2.

33. Velmahos GC, Degiannis E, Souter I, Allwood AC, Saadia R. Outcome of a strict policy on emergency department thoracotomies. Arch Surg. 1995;130(7):774-7.

34. Rothenberg SS, Moore EE, Moore FA, Baxter BT, Moore JB, Cleveland HC. Emergency Department thoracotomy in children — a critical analysis. J Trauma. 1989;29(10):1322-5.

35. Shimazu S, Shatney CH. Outcomes of trauma patients with no vital signs on hospital admission. J Trauma. 1983;23(3):213-6.

Como citar este artigo:

Fraga GP, Genghini EB, Mantovani M, Cortinas LGO, Prandi Filho W. Toracotomia de reanimação: racionalização do uso do procedimento. Rev Col Bras Cir. [periódico na Internet] 2006 Nov-Dez;33(6). Disponível em URL: www.scielo.br/rcbc

Endereço para correspondência:

Gustavo Pereira Fraga

Av. Coronel Silva Telles 211, apto 3

CEP: 13024-000 Cambuí

Campinas -SP

fragagp@uol.com.br 